\title{
COOPERAÇÃO TERRITORIAL EUROPEIA E CULTURA EM PORTUGAL ${ }^{*}$
}

\author{
Francisco José Veiga \\ Núcleo de Investigação em Políticas Económicas da Universidade do Minho, Portugal \\ Francisco Carballo-Cruz \\ Núcleo de Investigação em Políticas Económicas da Universidade do Minho, Portugal

\section{Linda Gonçalves Veiga} \\ Núcleo de Investigação em Políticas Económicas da Universidade do Minho, Portugal
}

\begin{abstract}
Resumo: Neste artigo é efetuada uma análise dos programas de Cooperação Territorial Europeia (CTE), nomeadamente, na sua dimensão cultural, assim como da sua aplicação em Portugal nos dois últimos períodos de programação. Com o intuito de analisar o financiamento da cultura em Portugal através dos programas CTE, é efetuado um levantamento dos projetos da área da cultura financiados por estes programas nos períodos de programação 2000-2006 e 2007-2013. A análise em detalhe dos projetos culturais em que participaram entidades portuguesas é complementada com a identificação e discussão de um conjunto de aspetos qualitativos sobre os projetos e programas de CTE, a partir das experiências e perspetivas das entidades envolvidas nos mesmos em Portugal. Da análise efetuada são extraídas várias conclusões e recomendações de política cultural.
\end{abstract}

Palavras-chave: Cooperação Territorial Europeia; Cultura; Desenvolvimento Económico.

\section{Introdução}

Nos últimos anos, a cultura tem assumido uma importância crescente como elemento de alavanca do desenvolvimento económico e social. Para além dum ativo intangível de qualificação e transmissão de experiências e vivências sociais, a cultura tem vindo a revelar-se como um sector com um elevado potencial de geração de riqueza e emprego.

Do lado da procura, a cultura é vista como um bem de consumo individual ou coletivo com uma notável capacidade de geração de externalidades positivas. Do lado da oferta, a cultura é entendida como um sector de atividade que, na sua aceção mais contemporânea, tem vindo a denominar-se Indústrias Culturais e Criativas (ICC). Estas

\footnotetext{
* Este artigo é parcialmente baseado no estudo Cooperação Territorial Europeia e Cultura realizado pelos autores, no âmbito do Plano de Estudos - Cultura 2020 da Secretaria de Estado da Cultura. O estudo encontra-se disponível em: http://www.gepac.gov.pt/gepac-seminarios/cultura2020/estudo-4-relatoriodocx.aspx.
} 
são definidas pela Comissão Europeia no Green Paper sobre ICC como "aquelas indústrias que usam a cultura como input e têm uma dimensão cultural, embora os seus outputs sejam essencialmente funcionais" (Comissão Europeia, 2010a). A associação e inclusão de atividades criativas ao/no sector da cultura tem dado mais visibilidade ao seu papel em termos de desenvolvimento económico e social.

O reconhecimento da importância da cultura como sector de atividade económica não é exclusivo da União Europeia. Outras instituições internacionais, nomeadamente as Nações Unidas (2008, 2010 e 2013) e a OCDE (2005 e 2009), têm publicado análises sectoriais enfatizando a relevância do sector em diferentes âmbitos. Para além do desenvolvimento em sentido lato, estas entidades têm destacado a estreita ligação entre cultura e ICC e desenvolvimento regional e local. As componentes territoriais da criatividade e da cultura estão presentes também na literatura académica. O papel das cidades (Florida, 2005), das regiões (Department of Culture, Media and Sport, 2001) e dos clusters (Cooke e Lazzeretti, 2008 e Power e Nielsen, 2010) tem sido sublinhado na dimensão espacial das ICC.

Na Europa, a cultura tem sido financiada pelos fundos da política de coesão, nos vários períodos de programação. No último, entre 2007 e 2013, os fundos disponíveis para o efeito foram consideravelmente reforçados, nomeadamente através dos programas de financiamento convencionais. Adicionalmente, a cultura e as ICC foram fortemente apoiadas pelos programas de cooperação territorial europeia (CTE). O financiamento por esta via resulta do reconhecimento, por um lado, da importância do intercâmbio de know-how, experiências e boas práticas no âmbito cultural e, por outro, da relevância da cultura para o desenvolvimento regional e local.

O objetivo fundamental deste artigo é analisar o financiamento da cultura em Portugal através dos programas CTE. Com essa finalidade é efetuado um levantamento dos projetos da área da cultura financiados por estes programas nos períodos de programação 2000-2006 e 2007-2013. São analisados com detalhe os projetos culturais em que participaram entidades portuguesas, classificando-os em função de diversas dimensões. Essa análise é complementada com a identificação e discussão de um conjunto de aspetos qualitativos sobre os projetos e programas CTE, a partir das experiências e perspetivas das entidades envolvidas nos mesmos em Portugal.

O resto do artigo organiza-se da seguinte forma. Na secção 2 revisa-se a relação entre cultura, economia e território, enquadra-se a CTE na política de coesão e analisa-se o encaixe da cultura nos programas de CTE. Na secção 3, explica-se a metodologia utilizada. O diagnóstico da participação portuguesa em projetos de índole cultural 
financiados com recursos da CTE é apresentado na secção 4. Na secção 5, sistematizam-se e discutem-se os resultados das entrevistas realizadas a gestores de projetos baseados na cultura, liderados por entidades portuguesas, e a responsáveis de programas de CTE em Portugal. Na secção 6, apresentam-se as principais conclusões e recomendações.

\section{Cooperação Territorial Europeia e Cultura}

\subsection{Cultura, economia e território}

Apesar do número crescente de iniciativas bem-sucedidas de desenvolvimento regional e local baseadas na cultura (Sacco et al. 2008 e 2009) e da relevância dos impactos apurados pelos primeiros estudos sobre a dimensão económica do setor cultural e criativo na Europa (KEA, 2006), o reconhecimento da importância da cultura para a competitividade estratégica da Europa é ainda escasso (Centre for Strategy and Evaluation Services, 2010). Por esse motivo, em momentos de crise como o atual, as atividades culturais são um dos primeiros e mais fáceis alvos de cortes nas despesas públicas. Para contrariar esta realidade, é fundamental enfatizar a importância da cultura nas agendas políticas nacional e Europeia, assim como garantir montantes de recursos suficientes para financiar iniciativas de índole cultural.

No debate sobre o contributo da cultura no desenvolvimento regional e local, o Conselho da União Europeia (2010) tem sublinhado a importância de incorporar a cultura, pelo seu caracter estratégico e transversal, em vários âmbitos das políticas públicas e em diversos domínios de intervenção. Tem salientado também a necessidade de incentivar o investimento na cultura e nas ICC, a nível regional e local, de promover o contributo da cultura para a melhoria da atratividade regional e local, de adotar políticas regionais e locais para a geração de competências através da cultura e da criatividade e, finalmente, de reforçar as iniciativas culturais transfronteiriças, transnacionais e inter-regionais como forma de ligar pessoas e reforçar a coesão económica, social e territorial.

O potencial da cultura como veículo de desenvolvimento é também reconhecido pelas Nações Unidas e a OCDE. Os relatórios Creative Economy (Nações Unidas, 2008 e 2010) demonstram que as atividades criativas constituem um dos sectores com maiores níveis de crescimento à escala global e evidenciam a sua elevada capacidade transformadora em matéria de geração de rendimento, emprego e receita de exportação. A edição de 2013 (Nações Unidas, 2013), explora diversos vetores de desenvolvimento baseados nas indústrias culturais e criativas e analisa a forma de reforçá-los e qualificá-los para garantir um desenvolvimento económico e social 
inclusivo. O relatório salienta que muitos desses vetores podem ser potenciados ao nível regional e urbano. A dimensão territorial do sector cultural e criativo aparece destacada também em vários documentos da OCDE. Os relatórios Cultural and Local Development (Organização para a Cooperação e Desenvolvimento Económico, 2005) e Impact of Culture on Tourism (Organização para a Cooperação e Desenvolvimento Económico, 2009) analisam, respetivamente, o potencial da cultura para o desenvolvimento local e a relação entre turismo, cultura e a atratividade e competitividade dos destinos.

A política de coesão europeia reconhece o papel da cultura no âmbito dos objetivos de convergência, competitividade e emprego e cooperação territorial (Comissão Europeia, 2010b). O aumento da importância da cultura no seio da política de coesão pode ser explicado pelo alargamento do que se entende por cultura. Para além do seu valor per se e como ativo para o desenvolvimento de sectores de atividade relacionados, a cultura é entendida como um elemento indutor da capacidade de atração de recursos humanos qualificados por parte de cidades e regiões. Por estes motivos, a cultura e os setores criativos deverão ser progressivamente integrados nas estratégias de desenvolvimento regional e local (KEA, 2012).

A cultura tem contribuído de várias formas para os objetivos definidos na política de coesão. Algumas intervenções culturais financiadas por fundos estruturais extravasam os limites do sector cultural, surgindo em áreas como a regeneração urbana, a renovação de zonas industriais abandonadas, o combate ao desemprego nos setores cultural e criativo, o apoio ao empreendedorismo, o apoio à inovação, a melhoria no acesso ao financiamento para as PME no setor criativo, a introdução das artes cénicas e da arte contemporânea na formulação de políticas, o incentivo à criatividade dos talentos, a diferenciação da imagem e marca das cidades e a partilha de boas práticas na aprendizagem recíproca na Europa.

\subsection{A Cooperação Territorial Europeia na Política de Coesão}

O principal objetivo da CTE é garantir o equilíbrio e a sustentabilidade do desenvolvimento de todo o território comunitário (Conselho da União Europeia, 2006). Como parte integrante da política de coesão, a CTE contribui para a cooperação transfronteiriça, transnacional e regional, estabelecendo um quadro conjunto de ação e intercâmbio de políticas (Comité Económico e Social Europeu, 2012). O foco da CTE tem vindo a orientar-se para a resolução de problemas, através da cooperação das partes envolvidas e da repartição de custos, e para a partilha de experiências e boas práticas entre diferentes tipos de agentes territoriais. 
Nas primeiras etapas da política regional, a coesão económica e social foi assegurada apenas por ações comunitárias que visavam colmatar as disparidades em termos de rendimento e emprego. Nas últimas duas décadas, a cooperação territorial tem assumido maior relevância na agenda política europeia, fruto da maior importância atribuída à definição de políticas para a coesão territorial, do maior envolvimento dos governos subnacionais nas políticas europeias e da consolidação da cooperação territorial como um elemento essencial na integração europeia (Spinaci e Vara-Arribas, 2009).

A perspetiva territorial da coesão económica e social está plasmada no Green Paper sobre Coesão Territorial Europeia, no qual se realça a importância da coesão territorial como forma de garantir o desenvolvimento harmonioso das regiões, garantindo aos seus habitantes a possibilidade de tirar proveito das suas especificidades, fazendo da diferença uma vantagem e contribuindo, desta forma, para o desenvolvimento sustentável da UE (Comissão Europeia, 2008). Deste modo, a política de coesão pode melhorar a coesão territorial por meio: i) da promoção de uma abordagem funcional ao desenvolvimento integrado dos territórios; ii) do desenvolvimento de políticas de base territorial, que assentem na coordenação inter-setorial de políticas e da governação a vários níveis; iii) da promoção da cooperação entre territórios, a fim de reforçar a integração europeia, e; iv) do reforço do conhecimento dos territórios para fundamentar as correspondentes estratégias de desenvolvimento.

A cooperação territorial europeia é, desde o período de programação 2007-2013, um dos objetivos prioritários da política de coesão. $O$ reforço da cooperação transfronteiriça, transnacional e inter-regional foi identificado como um domínio prioritário nas políticas de desenvolvimento regional e local, assim como na implementação da política de coesão europeia (Conselho da União Europeia, 2010). No contexto atual, a abordagem cooperativa da CTE é de extrema importância, tendo em consideração que os desafios que enfrentam as regiões e os Estados membros extravasam as fronteiras nacionais e regionais, requerendo, por isso, medidas de cooperação conjunta na escala de intervenção territorial mais adequada.

Nos períodos de programação anteriores a 2007, a cooperação territorial tinha um alcance muito mais modesto. A precursora da CTE foi a iniciativa comunitária INTERREG, lançada em 1990. Esta iniciativa tinha como objetivo genérico o reforço da coesão económica e social na UE. O INTERREG I centrou-se na promoção da cooperação transfronteiriça, com o objetivo de ajudar as regiões de fronteira a prepararem-se para o Mercado Único. O INTERREG II alargou o espectro do INTERREG I, ao aprofundar a dimensão da cooperação transfronteiriça e alargar o seu 
âmbito de intervenção à cooperação inter-regional. O INTERREG III aumentou ainda mais o contexto de intervenção de INTERREG. Desta forma, no período de programação 2000-2006, esta iniciativa comunitária organizou-se em três capítulos com objetivos bem-definidos: i) Capítulo A - cooperação transfronteiriça; ii) Capítulo B - cooperação transnacional; e iii) Capítulo C - cooperação inter-regional.

A conceção da CTE, no período de programação 2007-2013, baseou-se nas experiências de cooperação anteriores, sobretudo no INTERREG III. Ao tornar-se um dos três objetivos da política de coesão, a CTE adquiriu um estatuto jurídico mais elevado. No período 2007-2013 este objetivo da política de coesão dispôs de uma dotação aproximada de 8.700 milhões de euros (2,5\% dos fundos do FEDER). Nesse período, a CTE assumiu uma arquitetura similar ao INTERREG III, contemplando os três tipos de cooperação anteriormente referidos: transfronteiriça (1,5\% do FEDER), transnacional (o,5\% do FEDER) e inter-regional (o,5\% do FEDER).

No período de programação 2007-2013, a Comissão propôs uma regulamentação independente para a CTE, que tivesse em consideração a natureza multinacional dos programas e permitisse a adoção de disposições específicas para os programas e operações de cooperação. ${ }^{1}$ Propôs também a concentração de programas até em quatro objetivos temáticos, a descomplexificação da gestão dos programas (fusão de autoridades certificadoras e gestoras) e a simplificação do processo de criação e gestão dos Agrupamentos Europeus de Cooperação Territorial (AECT). ${ }^{2}$

\subsection{A Cultura na Cooperação Territorial Europeia}

A CTE tem demonstrado ser uma ferramenta particularmente importante para o intercâmbio de ideias em matéria de políticas de inovação, na promoção de uma identidade cultural comum e na preservação e promoção do património cultural, contribuindo assim para o estabelecimento de uma Europa inteligente, sustentável e coesa (INTERACT, 2013). A promoção do crescimento, do emprego e da melhoria da qualidade de vida pode ser alcançada quer através de ideias e estratégias inovadoras, quer através da educação, da capacitação institucional e da profissionalização dos recursos humanos.

\footnotetext{
${ }^{1}$ Proposta de Regulamento do Parlamento Europeu e do Conselho pelo que se estabelecem as disposições específicas relativas ao apoio do Fundo Europeu de Desenvolvimento Regional ao objetivo de Cooperação Territorial Europeia, COM (2011) 611 final/2, de 6 de outubro de 2011.

${ }^{2}$ Com esta última finalidade foi apresentado um novo Regulamento: Proposta de Regulamento do Parlamento Europeu e do Conselho pelo que se modifica o Regulamento (CE) núm. 1082/2006 do Parlamento Europeu e do Conselho, de 5 de julho de 2006, sobre o Agrupamento Europeu de Cooperação Territorial (AECT), no relativo à clarificação, simplificação e melhoria da criação e entrada em funcionamento destes Agrupamentos, COM (2011) 610 final/2, de 14 de março de 2012.
} 
A cultura e as indústrias criativas constituem parceiros naturais dos programas de cooperação territorial. A cultura facilita a ligação a outras regiões ou territórios, configura áreas de cooperação territorial e redes urbanas inovadoras e pode dinamizar o intercâmbio e a transferência de boas práticas, tanto no sector cultural como noutros sectores ou domínios. Embora não existam muitos estudos que discutam, analisem ou avaliem os projetos de índole cultural financiados pelos programas de CTE, nos últimos anos têm sido publicados alguns que se debruçam sobre o seu contributo para o desenvolvimento regional ou para o desenvolvimento sectorial.

O estudo Centre for Strategy and Evaluation Services (2010) analisa a contribuição para o desenvolvimento regional de intervenções baseadas na cultura apoiadas por fundos estruturais e de coesão, durante o período de programação 2000-2006. De acordo com os seus resultados, as principais fontes de financiamento dos projetos culturais durante esse período foram: Programas Operacionais (PO) nacionais, PO destinados a indústrias ou áreas específicas (e.g. PO para o turismo, renovação e desenvolvimento urbano, ambiente ou transportes), PO regionais e Iniciativas Comunitárias (e.g. INTERREG ou Urban Equal). No estudo conclui-se que os países do Sul revelaram maior interesse em financiar atividades culturais através dos Fundos Estruturais que os países do Norte. Outro resultado relevante é que existem diferenças significativas entre países, quanto ao tipo de intervenções e às atividades apoiadas.

O relatório European Territorial Cooperation - Inspiring Creativity (INTERACT, 2013) sistematiza as principais tendências no campo das ICC e apresenta as principais atividades e projetos relacionados com as ICC financiados com fundos comunitários. No estudo foram sinalizados 3.884 projetos de CTE (55\% do total de programas), dos quais, à volta de $15 \%$ se enquadravam nas ICC (583 projetos). De acordo com o estudo, entre 2007 e 2013, 11\% dos 8,7 biliões de euros do orçamento do objetivo de CTE financiaram projetos culturais e criativos (cerca de 1,02 biliões de euros), bem acima do valor inicialmente previsto para as iniciativas baseadas na cultura no âmbito deste objetivo da política de coesão (cerca de 470 milhões de euros). ${ }^{3}$ Estes resultados atestam a crescente importância da cultura nos processos de desenvolvimento regional, justificada pela estreita relação entre cultura e identidade e entre sectores criativos e criação de emprego.

De acordo com a mesma fonte, do total da despesa destinada a projetos culturais no âmbito da CTE, 236 milhões de euros foram canalizados para as indústrias criativas, 420 milhões de euros para as artes, 64 milhões de euros para as indústrias culturais e

3 http://ec.europa.eu/culture/documents/2007-2013_cohesion_policy.pdf. 
299 milhões de euros para o turismo cultural. As principais atividades financiadas estavam relacionadas com a preservação do património cultural e o fomento de plataformas de aprendizagem. O estudo conclui ainda que os projetos das ICC acrescentam valor ao contribuírem para o surgimento de novos e mais competitivos mercados nas regiões transfronteiriças, ao estimularem a partilha e transferência de conhecimentos e competências entre regiões de diferentes países e ao promoverem a identidade e imagem territorial.

\section{Metodologia: Mapeamento e entrevistas a agentes qualificados}

A abordagem metodológica adotada assenta numa perspetiva multi-método, que combina os seguintes procedimentos metodológicos:

- Recolha e tratamento de informação de fontes estatísticas secundárias sobre os projetos de CTE financiados por fundos europeus, com vista à construção de indicadores de síntese que informem o diagnóstico da situação em Portugal;

- Levantamento de opiniões e pontos de vista fundamentados na experiência, através de entrevistas semiestruturadas a gestores e coordenadores de programas e responsáveis de projetos de CTE baseados na cultura em Portugal.

Devido à inexistência de uma base de dados completa sobre os projetos de CTE, para mapear os projetos de índole cultural neste domínio tornou-se necessário construir uma base de dados, a partir de diversas fontes de informação. Este mapeamento é fundamental para levar a cabo o diagnóstico da situação atual em matéria de cooperação cultural europeia em Portugal e caracterizar os projetos financiados no âmbito da CTE.

O processo de mapeamento iniciou-se com a recolha da informação disponível na base de dados KEEP - Knowledge and Expertise in European Programmes. ${ }^{4}$ Esta base de dados disponibiliza informação sobre 43 programas e 3.045 projetos de CTE para o período de programação $2000-2006$ e sobre 76 programas e 5.617 projetos para o período de programação 2007-2013.

Dado que uma componente importante do diagnóstico tem como finalidade identificar o financiamento captado por parceiros portugueses, tornou-se necessário recorrer a fontes alternativas, uma vez que a informação disponibilizada na KEEP apenas se refere aos montantes de financiamento total. O financiamento aprovado por parceiro para cada projeto foi retirado dos sites dos nove programas do período de programação

${ }_{4}^{4}$ A KEEP é a base de dados gratuita mais completa que existe sobre projetos de CTE entre os países membros da União Europeia e entre esses e os países vizinhos (http://www.territorialcooperation.eu/keep/). 
2007-2013 em que Portugal participou: i) PO de Cooperação Transfronteiriça EspanhaPortugal - POCTEP; ii) Programa Multilateral de Cooperação Transfronteiriça da Bacia Marítima do Mediterrâneo - ENPI CBC MED; iii) PO de Cooperação Transnacional Espaço Atlântico; iv) PO de Cooperação Transnacional Madeira-Açores-Canárias MAC; v) PO de Cooperação Transnacional Bacia do Mediterrâneo - MED; vi) PO de Cooperação Transnacional Espaço Sudoeste Europeu - SUDOE; vii) European Observation Network for Territorial Development and Cohesion - ESPON; viii) PO de Cooperação Inter-regional INTERREG IV C, e; ix) URBACT II - European exchange and learning programme for promoting sustainable urban development. 5

Para a identificação dos projetos de CTE da área da cultura adotaram-se duas abordagens: uma restrita e outra abrangente. No âmbito da primeira, foram considerados projetos culturais aqueles em que uma das três palavras-chave dos projetos na base de dados KEEP correspondia a "Cultural heritage and arts." Aos identificados por este procedimento acrescentaram-se os incluídos na Medida 4.2 "Support to the artistic creativity in all its expressions to encourage dialogue among communities", do ENPI CBC MED; no Objetivo 4.3 - "Conserve and promote Atlantic cultural heritage of transnational interest”, do Espaço Atlântico, e; no Subtema "Cultural heritage and landscape", do INTERREG IV C.

Dado que vários projetos, cujo título ou descrição indicavam tratar assuntos da área da cultura, não foram contemplados na abordagem restrita, decidiu-se adotar complementarmente uma abordagem abrangente. Esta aproximação permitiu classificar também como culturais projetos cujo título ou descrição incluía uma ou mais de um conjunto de 74 palavras-chave relacionadas com a cultura. ${ }^{6}$ Depois de sinalizar os projetos não contemplados na definição restrita que continham pelo menos uma das palavras-chave consideradas, procedeu-se à leitura da sua descrição, a fim de verificar se efetivamente pertenciam à área da cultura. ${ }^{7}$ Para além dos projetos identificados seguindo a metodologia descrita, foram incluídos na abordagem abrangente projetos de

\footnotetext{
5 Para confirmar os montantes de financiamento e obter informação em falta foram estabelecidos contactos com os serviços do Instituto Financeiro para o Desenvolvimento Regional (IFDR). Os dados fornecidos sobre o financiamento aprovado para os parceiros portugueses participantes em projetos de CTE, no período de programação 2007-2013, referem-se a 30 de junho de 2013. Em casos pontuais, em que a falta de informação persistia, foram assumidos determinados pressupostos para a alocação dos montantes de financiamento entre parceiros. Em caso de discordância nos valores dos montantes, foram considerados os valores fornecidos pelo IFDR.

${ }^{6}$ A maioria das palavras-chave considerada foi proposta e utilizada no estudo ESSnet-CULTURE (2012). Os domínios culturais adotados nesse estudo foram utilizados também para classificar os projetos identificados, ainda que foram acrescentados mais dois: " 11 - Turismo Cultural" e " 12 - Interdisciplinar". 7 Esta filtragem justificou-se porque determinadas palavras-chave sinalizavam erradamente projetos de outras áreas. Por exemplo, com a palavra-chave "cultur" foram sinalizados projetos que tratavam temas relacionados com agricultura, silvicultura, floricultura ou aquacultura, entre outros.
} 
CTE de índole cultural não sinalizados, considerados culturais ou ligados às indústrias criativas pelo estudo elaborado pelo INTERACT Point Vienna (INTERACT, 2013). ${ }^{8}$

Com base nas abordagens descritas foi identificado um conjunto alargado de projetos culturais no contexto da CTE, nos dois períodos de programação. De acordo com a definição restrita de projeto cultural foram identificados 438 projetos no período de programação 2000-2006 e 803 projetos no período de programação 2007-2013. Com base na definição abrangente, foram mapeados um total de 1.869 projetos de âmbito cultural: 656 do período de programação 2000-2006 e 1.213 do período de programação 2007-2013.

Com vista à recolha de informação de natureza qualitativa sobre a participação de entidades portuguesas em projetos de cooperação territorial com componente cultural, recorreu-se à realização de entrevistas a responsáveis de entidades gestoras de projetos (chefes de fila) e de programas de CTE. A entrevista é uma técnica de investigação qualitativa que permite obter informação de forma personalizada (Ritchie e Lewis, 2003). No contexto deste estudo, as entrevistas permitiram compreender os motivos explicativos dos factos ou tendências subjacentes ao diagnóstico, confrontar os entrevistados com opiniões ou pontos de vista alternativos sobre diversos aspetos, fundamentar a avaliação do funcionamento dos programas, perspetivar o futuro dos programas em função da informação disponível e informar as recomendações de política.

As entrevistas efetuadas tiveram caráter semiestruturado. Este tipo de entrevistas baseia-se num guião elaborado antes da realização da entrevista, que limita tematicamente a interação entre os intervenientes. Não obstante esse balizamento, este tipo de entrevistas permite o relacionamento de temáticas diversas para melhorar a compreensão das matérias objeto de estudo, graças à sua flexibilidade e à possibilidade de acrescentar questões não incluídas no guião. As questões previstas no guião eram de caráter aberto, permitindo que o entrevistado realizasse comentários e matizações nas suas respostas, com vista a incrementar o valor acrescentado da iteração. ${ }^{9}$

Foram entrevistados os responsáveis de cinco dos treze projetos da área da cultura, do período de programação 2007-2013, com chefes de fila portugueses. ${ }^{10}$ Concretamente, foram entrevistados os responsáveis dos projetos: ${ }^{11}$ Creative Clusters (URBACT II),

\footnotetext{
8 Relativos ao período de programação 2007-2013.

9 O guião da entrevista está disponível nos anexos do estudo Cooperação Territorial Europeia e Cultura (http://www.gepac.gov.pt/gepac-seminarios/cultura2020/estudo-4-relatorio-docx.aspx).

${ }^{10}$ Abarcam cinco dos vários programas de CTE em que Portugal participa.

${ }^{11}$ A listagem das entidades está disponível nos anexos do estudo Cooperação Territorial Europeia $e$ Cultura (http://www.gepac.gov.pt/gepac-seminarios/cultura2020/estudo-4-relatorio-docx.aspx).
} 
Cruise Atlantic Europe (Espaço Atlântico), Incubators for Cultural Enterprises (Programa MED) e Instâncias Territoriais de Cooperação (POCTEP). Adicionalmente, embora a Comissão de Coordenação e Desenvolvimento Regional do Norte (CCDR-N) não tenha sido chefe de fila do projeto, pelas suas especiais características, foi entrevistada a responsável dessa entidade no projeto Vitour Landscape, liderado pela entidade italiana Parco Nazionale delle Cinque Terre.

Relativamente às entidades gestoras de programas de CTE, ${ }^{12}$ foram realizadas entrevistas no Instituto Financeiro para o Desenvolvimento Regional (IFDR), que assegura a coordenação nacional da participação portuguesa em programas de CTE, na Comissão de Coordenação e Desenvolvimento Regional - Norte (CCDR-N), que é o coordenador regional dos programas, e no Secretariado Técnico do PO de Cooperação Transnacional Espaço Atlântico (o único cuja entidade de gestão é portuguesa).

\section{Cooperação Territorial e Cultura: uma análise dos projetos financiados nos períodos de programação 2000-2006 e 2007-2013}

Nesta secção são apresentados os resultados do mapeamento dos projetos de CTE na área da cultura, efetuado com base nas abordagens e a partir das fontes de informação referidas na secção de metodologia. Deu-se especial destaque aos projetos com participação ou liderança portuguesa. De acordo com o nosso conhecimento, trata-se da análise mais completa sobre projetos de CTE relacionados com temáticas culturais realizado até a data em Portugal.

No Quadro 1 reportam-se dados relativos ao número de projetos de CTE, ao número de parceiros (entidades) envolvidos nos mesmos e ao respetivo financiamento europeu (FEDER). A informação refere-se aos períodos de programação de 2000-2006 e 20072013 e para os três tipos de cooperação territorial: transfronteiriça, transnacional e inter-regional.

Os dados apresentados permitem constatar que, em termos quantitativos, existe uma clara preponderância dos projetos de cooperação transfronteiriça, os quais representam 57\% do total em 2000-2006 e 78\% em 2007-2013. No entanto, no que se refere ao número de parceiros e ao financiamento, os programas de cooperação transnacional são dominantes no período 2000-2006 e os de cooperação transfronteiriça em 20072013. É de realçar também o considerável aumento do número de projetos e de parceiros e, sobretudo, do financiamento entre ambos os períodos. Relativamente aos

${ }_{12}$ A listagem das entidades está disponível nos anexos do estudo Cooperação Territorial Europeia e Cultura (http://www.gepac.gov.pt/gepac-seminarios/cultura2020/estudo-4-relatorio-docx.aspx). 
recursos disponibilizados, o financiamento total mais que triplica, passando de 1.801 M€ (milhões de euros) para 6.471 M€.

Quadro 1 - Projetos de Cooperação Territorial Europeia

\begin{tabular}{|c|c|c|c|c|c|c|}
\hline \multirow[b]{2}{*}{ Tipo de Cooperação } & \multicolumn{3}{|c|}{ 2000-2006 } & \multicolumn{3}{|c|}{$2007-2013$} \\
\hline & $\begin{array}{l}\text { No de } \\
\text { Projetos }\end{array}$ & $\begin{array}{l}\text { No de } \\
\text { Parceiros }\end{array}$ & $\begin{array}{l}\text { Financiamento } \\
\text { Europeu (em €) }\end{array}$ & $\begin{array}{l}\text { No }^{\circ} \text { de } \\
\text { Projetos }\end{array}$ & $\begin{array}{l}\text { No de } \\
\text { Parceiros }\end{array}$ & $\begin{array}{l}\text { Financiamento } \\
\text { Europeu (em } € \text { ) }\end{array}$ \\
\hline Transfronteiriça & 1.752 & 4.533 & $321.567 .709,00$ & 4.359 & 18.427 & $4.555 .053 .685,15$ \\
\hline Transnacional & 937 & 10.220 & $1.183 .706 .932,55$ & 931 & 9.525 & $1.546 .447 .453,63$ \\
\hline Inter-regional & 356 & 3.441 & $296.116 .052,63$ & 327 & 3.176 & 370.014.035,02 \\
\hline Total & 3.045 & 18.194 & $1.801 .390 .694,18$ & 5.617 & 31.128 & $6.471 .515 .173,80$ \\
\hline
\end{tabular}

Fontes: Portais na Internet do KEEP e dos programas POCTEP, ENPI CBC MED, Espaço Atlântico, MAC, MED, SUDOE, ESPON, INTERREG IVC e URBACT II. IFDR e Urbact Secretariat.

A informação relativa aos projetos de CTE com componente cultural é reportada no Quadro 2. Com base na definição abrangente foram identificados 656 projetos e 3.498 parceiros em 2000-2006 e 1.216 projetos e 5.866 parceiros em 2007-2013. Mais uma vez, a cooperação transfronteiriça é predominante a todos os níveis no período 20072013 e no número de projetos no período 2000-2006, enquanto a cooperação transnacional tem maior peso ao nível dos parceiros e do financiamento no período 2000-2006. Também se verifica um forte aumento no financiamento total, que mais que triplica de um período de programação para o outro, atingindo um montante de cerca de $992 \mathrm{M} €$ em 2007-2013, correspondente a 17,1\% do financiamento total de 6.471 M€ para projetos de cooperação territorial. 
Quadro 2 - Projetos de Cooperação Territorial Europeia da área da Cultura

\begin{tabular}{|c|c|c|c|c|c|c|}
\hline & 2000-200 & & & $2007-20$ & & \\
\hline Tipo de Cooperação & $\begin{array}{l}\text { No de } \\
\text { Projetos }\end{array}$ & $\begin{array}{l}\text { No de } \\
\text { Parceiros }\end{array}$ & $\begin{array}{l}\text { Financiamento } \\
\text { Europeu (em €) }\end{array}$ & $\begin{array}{l}\text { No de } \\
\text { Projetos }\end{array}$ & $\begin{array}{l}\text { No de } \\
\text { Parceiros }\end{array}$ & $\begin{array}{l}\text { Financiamento } \\
\text { Europeu (em €) }\end{array}$ \\
\hline Transfronteiriça & 409 & 1.001 & $70.805 \cdot 537,37$ & 1.071 & $4 \cdot 385$ & $779.897 .683,76$ \\
\hline Transnacional & 188 & 2.002 & 189.357.889,62 & 94 & 885 & $144 \cdot 305 \cdot 593,73$ \\
\hline Inter-regional & 59 & 495 & $51.261 .306,56$ & 51 & 596 & $67.736 .804,82$ \\
\hline Total & 656 & 3.498 & 311.424.733,55 & 1.216 & 5.866 & 991.940.082,31 \\
\hline
\end{tabular}

Fontes: Portais na Internet do KEEP e dos programas POCTEP, ENPI CBC MED, Espaço Atlântico, MAC, MED, SUDOE, ESPON, Interreg IVC e URBACT II. Base de dados de INTERACT (2013), IFDR e Urbact Secretariat.

Na Figura 1 apresenta-se o peso dos projetos liderados e de parceiros na área da cultura em Portugal e em quatro países com população similar, no total dos projetos e de parceiros na área da cultura. A percentagem de projetos liderados por entidades portuguesas é marginal (1,1\%); em termos comparativos, o peso dos projetos com chefe de fila português é consideravelmente inferior ao dos outros quatro países. No período 2007-2013, apenas 13 projetos da área da cultura foram liderados por entidades portuguesas. No mesmo período, entidades da Grécia e da Hungria lideraram 59 e 58 projetos, respetivamente. Com exceção da Bélgica, Portugal apresenta um número de parceiros inferior ao dos países de dimensão populacional similar utilizados como referência. Portugal apresenta também o pior rácio de projetos liderados por parceiro. Concretamente, apenas 1 em cada 14 entidades envolvidas em projetos de índole cultural é chefe de fila, o que se traduz num rácio de $1 / 14$. O segundo pior rácio é o da Bélgica, de 1/10, enquanto o da Grécia é de $1 / 4$ e o da Hungria é de quase 1/3. À luz destes dados, conclui-se que a frequência com que as entidades portuguesas lideram projetos na área da cultura é extremamente baixa. 
Figura 1 - Projetos da área da cultura e parceiros por país

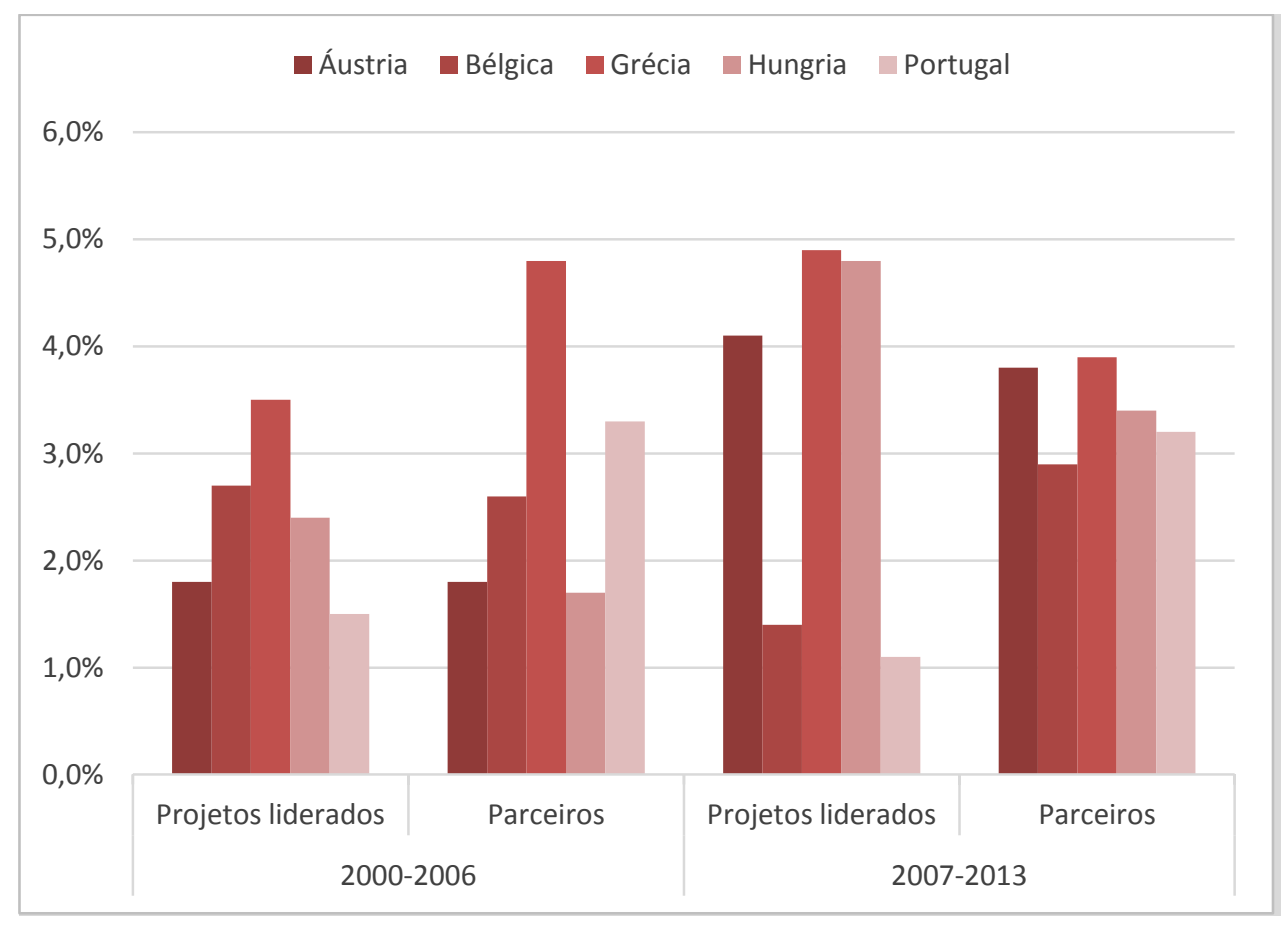

Fontes: Portais na Internet do KEEP e dos programas POCTEP, ENPI CBC MED, Espaço Atlântico, MAC, MED, SUDOE, ESPON, INTERREG IVC e URBACT II. Base de dados de INTERACT (2013). IFDR e Urbact Secretariat.

No período de programação 2007-2013, 190 entidades portuguesas foram parceiras de 84 projetos de índole cultural, beneficiando de um financiamento de cerca de $22 \mathrm{M€}$, que correspondeu a 19,6\% do financiamento para projetos com componente cultural nos nove programas de CTE em que Portugal participou. O PO de Cooperação Transfronteiriça Espanha-Portugal (POCTEP) é o que se destaca, contribuindo com mais de metade dos projetos (48) e com cerca de dois terços dos parceiros (139) e do financiamento (15,9 M€). Segue-se o programa INTERREG IVC, com 18 parceiros e 2,3 M€ de financiamento. Nos programas ENPI MED CBC e ESPON não houve qualquer projeto da área da cultura com parceiros portugueses.

Relativamente aos projetos em que participaram entidades portuguesas, a distribuição dos projetos, parceiros e financiamento por domínio cultural é apresentada na Figura 2. Em termos do número de projetos, destaca-se o domínio interdisciplinar com 27, seguido do turismo cultural com 23 e do património com 22 projetos. Em conjunto, estes três domínios culturais concentraram 85,7\% dos projetos. Em termos de parceiros e financiamento, o turismo cultural é preponderante, com quotas de 48,9\% e 49,7\%, 
respetivamente. Também nestas dimensões os projetos ligados ao património e ao domínio interdisciplinar acompanham o turismo cultural na liderança, com quotas a rondar os 20\%, em ambos os casos. Os restantes domínios culturais possuem uma importância relativamente reduzida. Em certos domínios, nomeadamente nos de 2Arquivos, 3-Bibliotecas, 8-Arquitetura e 9-Publicidade não foram identificados projetos da área da cultura com parceiros portugueses.

\section{Figura 2 - Projetos, parceiros e financiamento por domínio cultural}

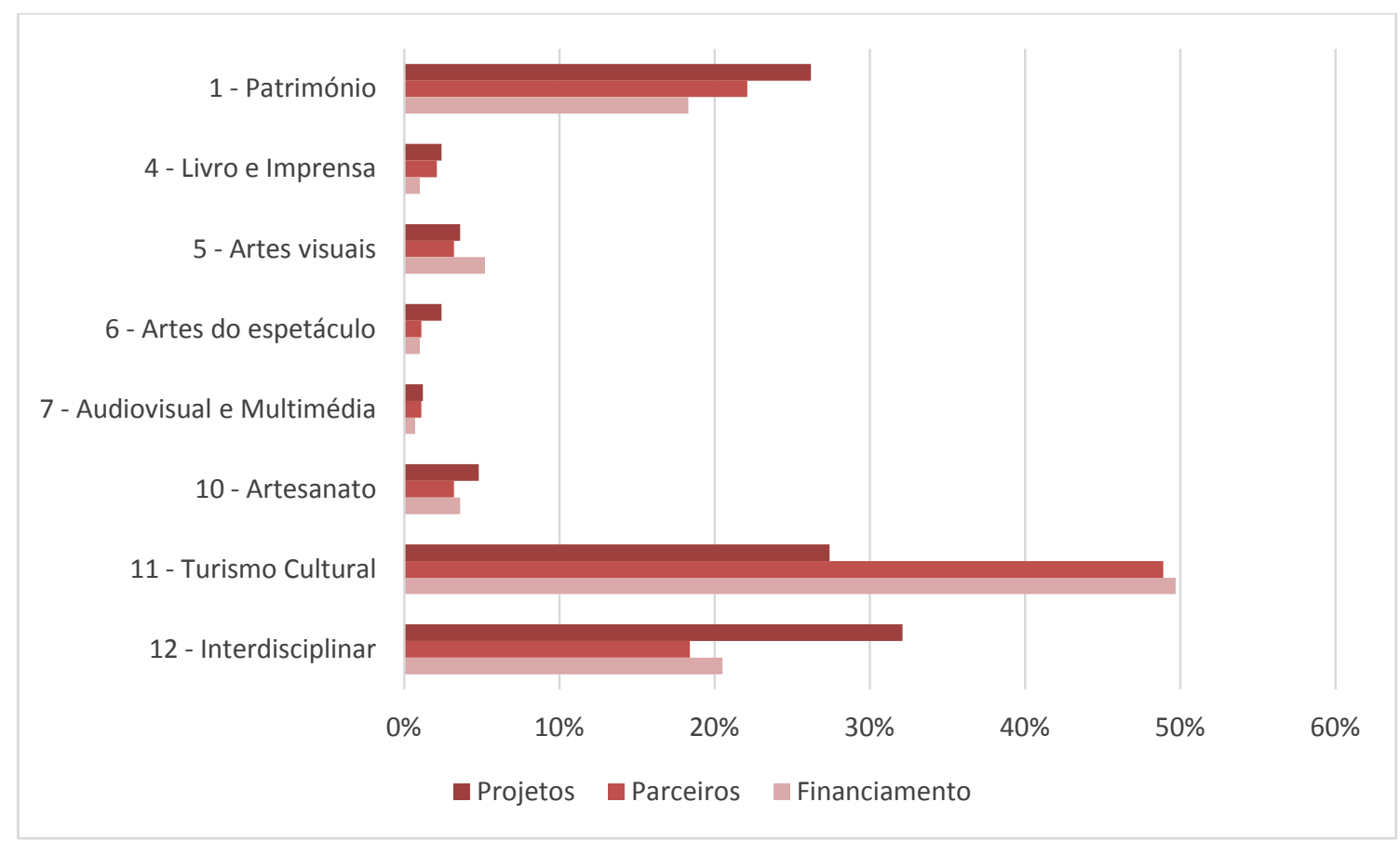

Fontes: Portais na Internet do KEEP e dos programas POCTEP, ENPI CBC MED, Espaço Atlântico, MAC, MED, SUDOE, ESPON, INTERREG IVC e URBACT II. Base de dados de INTERACT (2013). IFDR e Urbact Secretariat.

Das entidades portuguesas parceiras de projetos com conteúdo cultural, mais de metade (102 ou 54\%) são autarquias locais (ver Figura 3). Seguem-se as entidades pertencentes à administração central e regional (45 ou 24\%) e as do terceiro setor (34 ou 18\%). A participação de empresas nestes projetos de índole cultural é relativamente marginal, dado que apenas 9 entidades deste tipo foram parceiras nos mesmos. Das 13 entidades portuguesas que aparecem como chefe de fila, 6 pertencem ao terceiro setor, 4 são autarquias locais, 2 integram a administração central e regional e 1 é uma empresa. As entidades do terceiro setor representam apenas um quinto das entidades parceiras (18\%), mas lideram quase metade dos projetos com chefe de fila português 
(46\%). Contrariamente, as autarquias locais e a administração central e regional estão sub-representadas em termos de liderança dos projetos. Finalmente, relativamente ao financiamento, a distribuição é quase igual à dos parceiros, destacando-se as autarquias locais que absorvem $56 \%$ do financiamento total, que ascende a cerca de 12 milhões de euros.

Figura 3 - Líderes, parceiros e financiamento por tipo de entidade

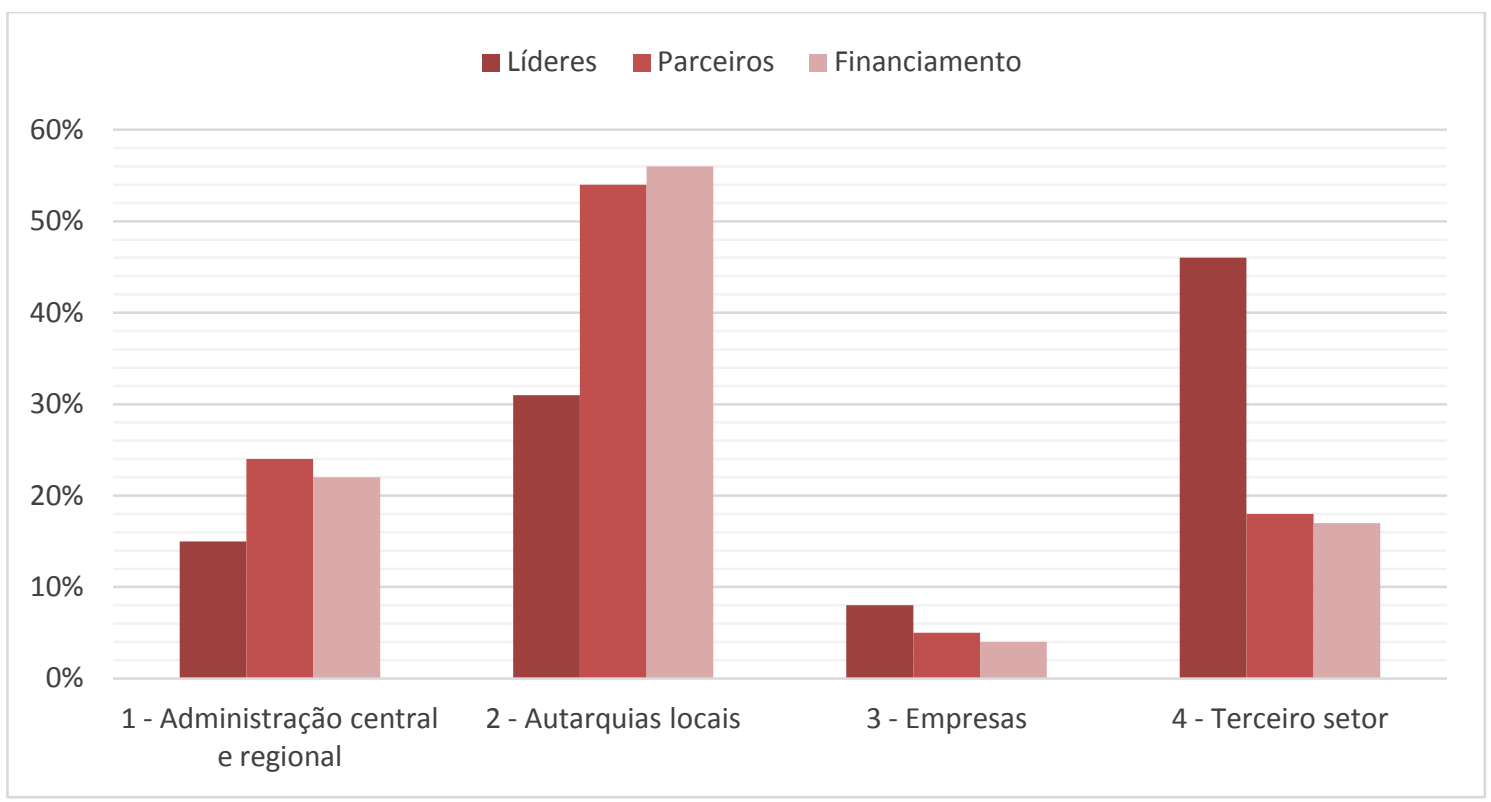

Fontes: Portais na Internet do KEEP e dos programas POCTEP, ENPI CBC MED, Espaço Atlântico, MAC, MED, SUDOE, ESPON, INTERREG IVC e URBACT II. Base de dados de INTERACT (2013). IFDR e Urbact Secretariat.

Cruzando os domínios culturais e os tipos de agentes foram identificados os domínios culturais de eleição para cada tipo de entidade parceira. O par dominante é autarquia local e turismo cultural, dado que 62 autarquias (quase um terço das 190 entidades portuguesas) participaram em projetos de turismo cultural. Seguem-se em ordem de importância, embora com uma expressão bastante menor, as combinações entidade da administração central e regional e património (18) e autarquia local e património (17). 


\section{Figura 4 - Financiamento para projetos da área da cultura por programa e país}

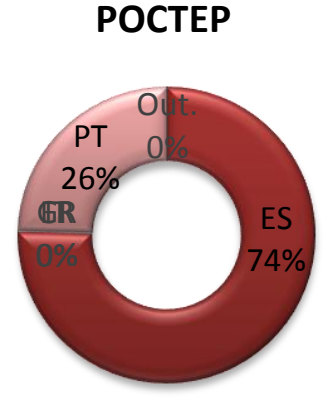

MAC

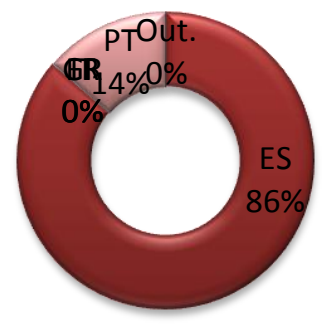

SUDOE

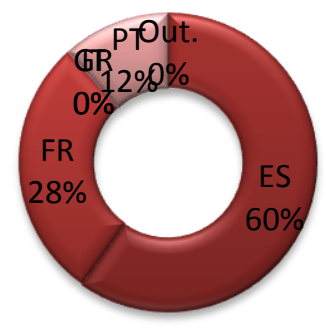

ENPI MED

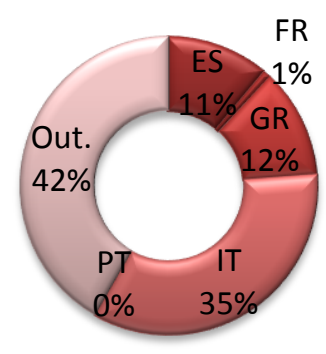

URBACT II

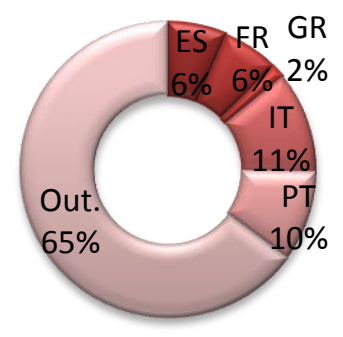

Interreg IVC

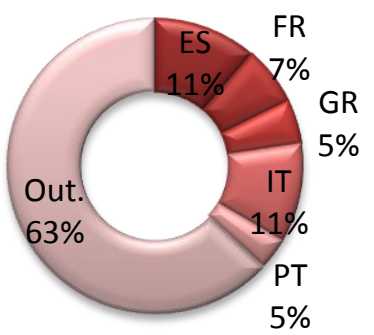

Atlântico

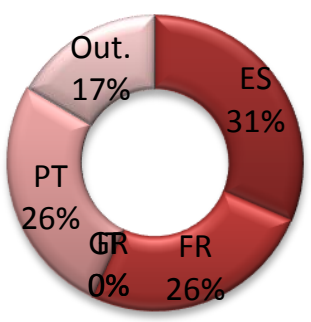

MED

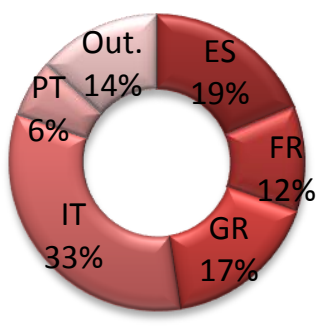

ESPON

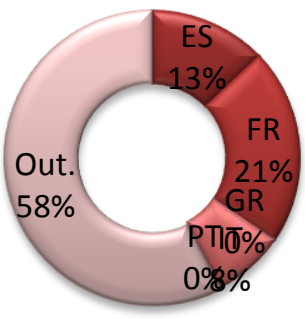

Fontes: Portais na Internet do KEEP e dos programas POCTEP, ENPI CBC MED, Espaço Atlântico, MAC, MED, SUDOE, ESPON, INTERREG IVC e URBACT II. Base de dados de INTERACT (2013). IFDR e Urbact Secretariat.

A repartição por país do financiamento para projetos com conteúdo cultural em cada um dos nove programas de CTE em que participou Portugal consta na Figura 4. A distribuição do financiamento nos PO de Cooperação Transfronteiriça EspanhaPortugal (POCTEP) e de Cooperação Transnacional Madeira-Açores-Canárias (MAC) evidencia a maior capacidade de captação de financiamento por parte dos parceiros espanhóis, que absorveram 74\% dos recursos financeiros do POCTEP e $86 \%$ dos do MAC para a área da cultura. Nestes PO os parceiros portugueses ficam com os restantes $26 \%$ no caso do POCTEP e $14 \%$ no caso MAC. A capacidade de captação de 
financiamento das entidades portuguesas é maior nos PO Espaço Atlântico e URBACT II. No Espaço Atlântico obtiveram 26\% do financiamento total, uma percentagem similar à da França e não muito inferior à da Espanha (31\%). Neste programa o financiamento recebido pelas entidades portuguesas ultrapassou o garantido por entidades do Reino Unido e da Irlanda. Relativamente ao programa URBACT II, Portugal é o segundo país em termos de captação de financiamento (10\%), apenas atrás da Itália (11\%) e à frente dos restantes 21 países que receberam financiamento ao abrigo deste programa em projetos da área da cultura.

\section{Cooperação Territorial e Cultura: A perspetiva dos beneficiários e dos responsáveis de coordenação e gestão de programas}

Com a finalidade de compreender as motivações e comportamentos das entidades portuguesas participantes em projetos de CTE da área da cultura, assim como avaliar a sua participação nos mesmos, foram entrevistados os responsáveis de cinco projetos de CTE, pertencentes a cinco dos programas vigentes durante o período de programação 2007-2013. Para validar a informação obtida e conhecer o funcionamento dos programas, foram igualmente entrevistados Responsáveis de Autoridades de Gestão dos Programas (Espaço Atlântico), Responsáveis Regionais pela Gestão de Programas de CTE (CCDR-N) e Coordenadores Nacionais de Programas de CTE (IFDR). ${ }^{13}$

A seguir são apresentadas de forma organizada as opiniões e posições maioritárias que foram expressas pelos representantes das entidades beneficiárias nas entrevistas realizadas. Constam apenas as opiniões que foram validadas pelos responsáveis de coordenação e gestão de programas, também de forma maioritária. Os pontos de vista dos entrevistados são, em alguns casos, completados com observações ou informações obtidas a partir de outras fontes.

As principais motivações apontadas pelas entidades portuguesas para participar em projetos de CTE de índole cultural são a partilha de experiências e soluções e o desenvolvimento de ideias para cobrir necessidades culturais ou relacionadas com a cultura, ou atrair e desenvolver negócios. Foram ainda referidas a diversificação, qualificação e complexificação sectorial e a potenciação de recursos locais e o contributo para a conceção de políticas públicas eficazes.

Relativamente ao sucesso das candidaturas, existe um conjunto de aspetos que os entrevistados consideraram chave, nomeadamente, a qualidade da parceria, a

${ }_{13}$ Os guiões das entrevistas e as listas de entidades entrevistadas estão disponíveis nos anexos do estudo Cooperação Territorial Europeia e Cultura (http://www.gepac.gov.pt/gepacseminarios/cultura2020/estudo-4-relatorio-docx.aspx). 
pertinência do tema e a sua justificação, a experiência e capacidade do chefe de fila, a estrutura da candidatura, a repartição de tarefas e a razoabilidade do orçamento. A qualidade da parceria foi invocada por todos os entrevistados. As recomendações neste âmbito são a preparação atempada, a escolha de parceiros com valor acrescentado na temática do projeto, evitando, sempre que possível, a entrada de parceiros por compromisso, e a razoabilidade da repartição dos parceiros por países/regiões. Deve ser evitada, sempre que possível, a entrada nos projetos por arrastamento, para cumprir com os requisitos de multi-nacionalidade/multiregionalidade ou de tipologia de entidade (público/privada), exigíveis a uma parceria num projeto de CTE. Nos períodos de programação anteriores a 2007, houve uma quantidade apreciável de projetos transfronteiriços em que as atividades desenvolvidas em Portugal e em Espanha pouco tinham de comum e pouca interligação existia entre os parceiros envolvidos. Este tipo de situações é ainda frequente em alguns programas e, na opinião dos entrevistados, resulta da atitude pouco proactiva e da falta de cultura de cooperação dos parceiros portugueses, em geral, especialmente dos de menor dimensão. De todas formas, em alguns casos, justifica-se a criação de parcerias em cascata, quando o convite de uns parceiros por parte de outros serve como garantia de qualidade das escolhas.

Nos últimos períodos de programação, as consultoras especializadas têm-se erigido em agentes centrais nos processos de candidatura em programas de CTE. Embora o recurso a consultoras possa aumentar a probabilidade de sucesso de uma candidatura, também a pode desvirtuar, se as preocupações e necessidades das entidades não ficarem refletidas nos projetos. Apesar da maioria das experiências com consultoras não ser a melhor, o apoio das mesmas revela-se especialmente importante para entidades que não disponham de recursos humanos suficientes para lidar com a carga burocrática inerente à preparação de uma candidatura e à execução de um projeto.

A escolha do tema do projeto é outro assunto fundamental. Deve estar bem fundado nos objetivos e prioridades do programa, focando, sempre que possível, as dimensões que o programa tenciona privilegiar e o seu caráter inovador. A justificação das escolhas deve incluir a relevância da temática para a rede. Adicionalmente, deve ser explicada a forma em que o projeto contribui para os objetivos e prioridades específicas em que se insere e para o desenvolvimento e a coesão, no âmbito de uma estratégia de base territorial. Deste ponto de vista, afigura-se especialmente importante compreender as decisões de aprovação dos projetos por parte da autoridade de gestão e, no caso das áreas que não são explicitamente apoiadas pelo programa, efetuar leituras imaginativas dos termos das convocatórias. Na escolha dos conteúdos é 
fundamental evitar a artificialidade temática ou forçar a ligação ente temas e dimensões escassamente relacionadas. Deve igualmente ser evitada a elaboração unilateral das candidaturas (pelo chefe de fila ou por um pequeno grupo de parceiros).

A experiência e capacidade do chefe de fila acabam por ter uma importância considerável na preparação e montagem das candidaturas. A sua relação com a temática central do projeto é relevante, mas não tanto como noutro tipo de programas. As entidades devem estar conscientes das suas capacidades e das suas limitações. Nem todas as entidades reúnem as condições necessárias para ser chefe de fila, sobretudo no que respeita ao atempado tratamento de toda a carga burocrática envolvida e à folga financeira necessária para arrancar com o projeto. A falta de competências e capacidades administrativas, humanas e financeiras das entidades de menor dimensão condicionam o seu posicionamento na parceria e o seu potencial para exercer a liderança do projeto. Sendo este o perfil maioritário das entidades do sector cultural Português, é compreensível que, em geral, apareçam em posições de menor destaque.

A estrutura da candidatura e a repartição de tarefas, bem como a razoabilidade do orçamento foram também invocados nas entrevistas como aspetos a ter em consideração. A forma de organização dos conteúdos e a alocação de tarefas aos parceiros deve ser adequada e ter presente as competências dos mesmos. As tarefas incluídas devem responder aos objetivos do projeto, devendo evitar-se a inclusão de tarefas ou atividades próprias dos parceiros. Mais uma vez, a experiência das autoridades de gestão facilita a identificação deste tipo de práticas destinadas a financiar atividades dos parceiros e não atividades próprias do projeto. A determinação e repartição do orçamento devem ser presididas pela razoabilidade e a parcimónia. Em linha com a observação anterior, deve ter-se em consideração que os programas de CTE financiam projetos e não entidades.

Um aspeto considerado sumamente importante pelos entrevistados para garantir a apresentação de candidaturas a projetos de CTE, em quantidade e qualidade, é o trabalho de animação e dinamização de atores e redes. A responsabilidade destas atividades corresponde às autoridades nacionais e regionais, no caso português, ao Instituto Financeiro de Desenvolvimento Regional (IFDR) [atual Agência para o Desenvolvimento e Coesão (ADC)] e às Comissões de Coordenação e Desenvolvimento Regional (CCDR), respetivamente.

Um motivo de preocupação relativamente aos projetos financiados é o escasso número de parceiros e chefes de fila portugueses em alguns programas de CTE. Embora a menor capacidade administrativa e financeira e a menor iniciativa das entidades 
portuguesas face às suas congéneres europeias contribuam certamente para que assumam em menos ocasiões papéis de liderança, o FEDER indicativo de Portugal nos programas de CTE limita fortemente o número de chefes de fila e o financiamento global obtido por entidades portuguesas. Isto porque, sendo a aprovação dos projetos feita por consenso dos países participantes em cada programa, por muito boas que sejam as candidaturas portuguesas, os restantes países dificilmente aceitam ceder a Portugal parte dos seus montantes indicativos FEDER.

Relativamente à fase de execução, os entrevistados apontaram que, regra geral, os projetos tiveram um desempenho técnico em linha com o esperado ou inclusivamente superior. No entanto, a execução financeira tem sido relativamente baixa. Por um lado, porque os cortes nas dotações financeiras de muitas das entidades envolvidas, sobretudo das públicas, provocaram grandes dificuldades ao financiamento das atividades previstas. Por outro lado, porque o caráter reembolsável das despesas e a ausência de adiantamentos na maioria dos programas criaram graves entraves à execução dos projetos, pois o tempo de espera entre a realização da despesa e o reembolso efetivo da mesma ultrapassou frequentemente os seis meses, chegando, em certas ocasiões, aos doze meses.

O bom desempenho de alguns dos projetos selecionados tem sido sublinhado via passagem a fases de capitalização ou através da obtenção de reconhecimentos ao trabalho realizado. O projeto Incubators for Cultural Enterprises, do programa MED, liderado pela Comunidade Intermunicipal do Alentejo Central (CIMAC), passou à fase de capitalização. Este projeto tinha como objectivo promover a atividade artística e cultural com o intuito de impulsionar o desenvolvimento nas regiões inseridas no projecto, através do fortalecimento das pequenas e médias empresas ligadas ao sector cultural. A fase de capitalização, à qual apenas passam os melhores projetos, por convite das autoridades de gestão, destina-se ao reforço de redes, à consolidação e potenciação de parcerias e à perpetuação de resultados. O projeto capitalizado, também coordenado pela CIMAC, denomina-se $3 C_{4}$ Incubators. Insere-se genericamente na mesma temática e abrange um número superior de parceiros, procedentes de diversos projetos e, inclusivamente, de outros programas, nomeadamente do INTERREG IVC.

Outro dos projetos de índole cultural reconhecidos em termos de desempenho é o denominado Creative clusters in low density urban areas, liderado pela Câmara Municipal de Óbidos. Este projeto visou a promoção do desenvolvimento em zonas urbanas de baixa densidade, através de atividades recreativas e culturais e do desenvolvimento de empresas de alta tecnologia, clusters competitivos e redes de parceria, entre outros. O projeto, financiado pelo URBACT II, tem sido alvo de diversos 
reconhecimentos. O seu Local Action Plan foi um dos três escolhidos (de entre 200) pela autoridade de gestão para efeitos de follow-up, pela sua qualidade e pertinência. A dinâmica do projeto fez com que a Câmara de Óbidos fosse convidada a dar contributos para o Green Paper da CE sobre Indústrias Criativas. No domínio do desenvolvimento das ICC, Óbidos foi considerada, pela prestigiosa consultora KEA, como um dos 50 casos a acompanhar nos próximos anos na Europa. No seguimento do projeto Creative clusters in low density urban areas, a Câmara Municipal de Óbidos foi convidada a integrar 12 redes no âmbito do URBACT II. Um desses convites cristalizou num outro projeto do mesmo programa denominado Creative Spin.

Com a finalidade de identificar as principais limitações e competências dos parceiros portugueses que participaram nos projetos de CTE, solicitou-se aos entrevistados que identificassem os seus pontos fracos e fortes e os relacionassem com as ameaças e oportunidades que podem afetar o desempenho das entidades portuguesas, no âmbito destes programas, no próximo período de programação. Entre os pontos fracos destacam-se as limitações de recursos humanos e financeiros, derivadas da reduzida dimensão dos parceiros portugueses que participam nestes programas e da crise económico-financeira que tem afetado o país nos últimos anos. Como aspetos negativos foram elencados a dificuldade para lidar com as consultoras que operam no mercado de projetos e a escassa capacidade das entidades portuguesas para divulgar os seus resultados.

No período de programação 2014-2020, as limitações de recursos podem transformarse numa ameaça se continuarem a existir restrições financeiras no funcionamento dos serviços, bem como limitações para contratar. Esta ameaça é mais grave para as entidades do sector cultural, atendendo às dificuldades que historicamente têm existido em Portugal para financiar instituições e iniciativas de caráter cultural com recursos do orçamento do Estado. No âmbito financeiro, foi também apontada como uma ameaça a considerar a crescente financiarização dos programas e a possibilidade de que o instrumento do financiamento a fundo perdido perca importância face à previsível generalização de instrumentos de engenharia financeira no âmbito da política de coesão.

Entre os pontos fortes das entidades portuguesas foram referidas a flexibilidade ou adaptabilidade e a gestão da mudança, em alguns casos designada por criatividade na gestão ou por elevada capacidade de resposta. Os entrevistados indicaram também a preocupação dos chefes de fila portugueses com o envolvimento dos parceiros. Uma das oportunidades óbvias deste tipo de programas é o reforço das parcerias e das redes e a partilha de experiências e o benchmarking. Esta oportunidade foi apontada 
unanimemente por todos os entrevistados. Em termos latos, a CTE pode constituir uma oportunidade para as entidades do sector cultural pelo considerável montante de recursos que irão mobilizar alguns dos seus programas no período de programação 2014-2020. Note-se ainda que neste período há um incremento das taxas de cofinanciamento, as quais em alguns programas podem atingir $85 \%$ do montante total do projeto.

\section{Conclusões e recomendações}

Neste artigo foi efetuada uma análise dos programas de CTE, nomeadamente, na sua dimensão cultural, assim como da sua aplicação em Portugal nos últimos períodos de programação. As principais conclusões do estudo são descritas abaixo.

A cultura assume um papel cada vez mais determinante enquanto elemento promotor da competitividade dos territórios, gerador de emprego e riqueza, dinamizador da coesão social e territorial e instrumento de afirmação internacional das comunidades. O seu papel mais preponderante é ao nível local e regional.

A CTE é um dos objetivos da política de coesão. Este objetivo tem vindo a ganhar relevância na agenda política europeia, devido à maior importância concedida às políticas para a coesão territorial, ao maior envolvimento dos governos regionais e locais na definição e implementação das políticas europeias e ao reconhecimento do seu papel impulsionador do processo de integração europeia. O sector cultural e as ICC são parceiros naturais dos programas de CTE, dado que, por um lado, promovem a dimensão sociocultural e transnacional e, por outro, dinamizam o intercâmbio e a transferência de boas práticas em amplas áreas de cooperação e no território europeu.

No período de programação 2007-2013, Portugal recebeu à volta de 118 milhões de euros dos programas de CTE. O POCTEP, com 60,5 milhões de euros, o Espaço Atlântico, com 19,5 milhões de euros, o SUDOE, com 12,3 milhões de euros e o INTERREG IVC, com 7,4 milhões de euros concentram quase $85 \%$ dos recursos da CTE para Portugal, nesse período de programação. Em termos globais, as prioridades privilegiadas pelos vários programas foram a de Ambiente e Desenvolvimento Sustentável (38\%) e a de Inovação na Competitividade e Emprego (36\%).

De acordo com a definição abrangente de projeto cultural adotada neste estudo, no período de programação 2007-2013, 1.216 projetos de um universo de 5.617 têm caráter cultural. 5.866 parceiros, dos 31.128 que estiveram envolvidos em projetos de CTE, participaram em projetos de base cultural. Em termos de financiamento, os projetos 
culturais obtiveram 992 milhões de euros dos 6.471 milhões de financiamento foram alocados a projetos de CTE.

No período 2007-2013, 190 entidades portuguesas foram parceiras de 84 projetos de base cultural, beneficiando de um financiamento de cerca de 22 milhões de euros, que corresponde a 19,6\% do financiamento para projetos com componente cultural nos nove programas de CTE em que Portugal participou. Destaca-se o PO de Cooperação Transfronteiriça Espanha-Portugal, por concentrar mais de metade dos projetos, cerca de dois terços dos parceiros e 15,9 milhões de euros de financiamento. Segue-se o programa INTERREG IVC, com um quinto dos parceiros e 2,3 milhões de recursos FEDER. Nos programas ENPI MED CBC e ESPON não houve qualquer projeto da área da cultura com parceiros portugueses.

A distribuição dos projetos, parceiros e financiamento por domínio cultural é escassamente diversificada. Relativamente ao número de projetos em que participam entidades portuguesas, destaca-se o domínio interdisciplinar com 27, seguido do turismo cultural com 23 e do património com 22 projetos. No total, estes três domínios culturais abrangem aproximadamente $85 \%$ dos projetos. Nas distribuições por parceiro e financiamento, o turismo cultural assume uma posição de liderança, com quotas de cerca de $49 \%$ e $50 \%$, respetivamente.

Das entidades portuguesas parceiras de projetos com conteúdo cultural, mais de metade (54\%) são autarquias locais. Cerca de um quarto pertencem à administração central e regional (24\%) e quase um quinto ao terceiro setor (18\%). As empresas têm uma participação relativamente marginal em projetos de índole cultural (5\%), dado que apenas 9 participam como parceiros neste tipo de projetos. Das 190 entidades portuguesas, unicamente 13 aparecem como chefe de fila. Delas, 6 pertencem ao terceiro setor, 4 são autarquias locais e 2 são entidades da administração central e regional e a que resta é uma empresa privada.

As principais motivações apontadas pelas entidades portuguesas para participar em projetos de CTE de índole cultural são a partilha de experiências e soluções e o desenvolvimento de ideias para cobrir necessidades culturais ou relacionadas com a cultura, ou atrair e desenvolver negócios. Foram ainda referidas a diversificação, qualificação e complexificação sectorial e a potenciação de recursos locais e o contributo para a conceção de políticas públicas eficazes.

Existe um conjunto de aspetos-chave para garantir o sucesso das candidaturas aos projetos de CTE, nomeadamente, a qualidade da parceria, a pertinência do tema e a sua justificação, a experiência e capacidade do chefe de fila, a estrutura da candidatura, a 
repartição de tarefas e a razoabilidade do orçamento. Embora o recurso a consultoras possa aumentar a probabilidade de sucesso de uma candidatura, também a pode desvirtuar, se as preocupações e necessidades das entidades não forem tidas em consideração.

Na perspetiva dos beneficiários, os principais problemas durante a fase de execução destes projetos são os de carácter administrativo e financeiro. Em relação a estes últimos, as baixas taxas de execução são um indício dos mesmos. Os problemas neste domínio relacionam-se com os cortes nas dotações financeiras de muitas das entidades envolvidas, sobretudo as públicas, e com a ausência de adiantamentos e a utilização de um sistema de reembolsos com diversos níveis de controlo, que provoca atrasos consideráveis no recebimento das despesas efetuadas.

No período de programação 2014-2020 a cultura aparece marginalmente nas orientações temáticas da política de coesão. Concretamente, apenas é mencionada no objetivo seis do Regulamento do FEDER, no contexto da proteção, promoção $e$ desenvolvimento da herança cultural. Apesar da escassa presença explícita das iniciativas direta ou indiretamente relacionadas com a cultura nas prioridades de investimento, algumas delas permitem acomodar iniciativas de natureza cultural ou relacionadas com a cultura.

A dotação indicativa para os programas de CTE para Portugal, no período de programação 2014-2020, é de aproximadamente 107 milhões de euros. Desses recursos, mais de 60\% são destinados à cooperação transfronteiriça. A taxa de cofinanciamento nestes programas passa a ser de $85 \%$ do orçamento das intervenções.

Embora os recursos que poderão ser captados por projetos baseados na cultura nos programas de CTE devam ser modestos, os parceiros portugueses deverão manter uma atitude proactiva na formação de parcerias, na escolha de temáticas e na dinamização de redes. Neste âmbito o papel das diversas tutelas é extremamente importante. Estas devem promover a constituição, junto da Agência para o Desenvolvimento e Coesão e as Comissões de Coordenação e Desenvolvimento Regional, de uma bolsa de potenciais parceiros com interesse e capacidade em participar nos programas de CTE.

As autoridades com responsabilidade em matéria de política cultural devem incentivar a participação de entidades culturais nas ações de informação, formação e animação que venham a ser organizadas pela Agência para o Desenvolvimento e Coesão, as Comissões de Coordenação e Desenvolvimento Regional e as Autoridades de Gestão dos Programas. 
A propósito do eventual reforço futuro do objetivo de CTE, o governo português deve ter um papel ativo na definição das orientações estratégicas de Portugal neste domínio, promovendo o alargamento dos territórios cobertos por programas de CTE a países com os quais se partilhem elementos identitários relevantes, tais como a língua, a cultura ou o património. Nestas circunstâncias, os esforços devem concentrar-se na inclusão, a prazo, nos programas dos Países Africanos de Língua Oficial Portuguesa, em especial, da República de Cabo Verde por motivos de proximidade com os territórios insulares do nosso país.

\section{Referências Bibliográficas}

Centre for Strategy and Evaluation Services (2010) Study on the contribution of culture to local and regional development - Evidence from the structural funds, final report. Kent: Centre for Strategy and Evaluation Services.

Comissão Europeia (2008) Livro Verde sobre a Coesão Territorial Europeia - Tirar partido da diversidade territorial. Bruxelas: Comissão Europeia.

Comissão Europeia (2010a) Green Paper on Cultural and Creative Industries Unlocking the Potential of Cultural and Creative Industries. Bruxelas: DG Educação e Cultura, Comissão Europeia.

Comissão Europeia (2010b) The European Agenda for Culture - Progress Towards Shared Goals. Bruxelas: Comissão Europeia.

Comité Económico e Social Europeu (2012) Proposta de regulamento do Parlamento Europeu e do Conselho que estabelece as disposições específicas para o apoio do Fundo Europeu de Desenvolvimento Regional ao objetivo de Cooperação Territorial Europeia. Bruxelas: Comité Económico e Social Europeu.

Conselho da União Europeia (2006) Decisão do Conselho relativa às orientações estratégicas comunitárias em matéria de coesão, Jornal Oficial L 291 de 6 de outubro de 2006, 11-31.

Conselho da União Europeia (2010) Conclusões do Conselho sobre o contributo da cultura para o desenvolvimento regional e local, Jornal Oficial C 135 de 26 de maio de 2010, $15-18$. 
Cooke, Philip \& Lazzeretti, Luciana (2008) (eds.) Creative cities, cultural clusters and local economic development. Cheltenham: Edward Elgar.

Department of Culture, Media and Sport (2001) Creative Industries Mapping Document 2001. Londres: Department of Culture, Media and Sport.

ESSnet-Culture (2012) ESSnet-Culture Final Report, Luxemburgo: European Statistical System Network on Culture.

Florida, Richard (2005) Cities and the creative class. Nova Iorque: Routledge.

INTERACT (2013) European Territorial Cooperation - Inspiring Creativity. Viena: INTERACT Publications.

KEA (2006) The Economy of Culture in Europe. Bruxelas: KEA European Affairs.

KEA (2012) Use of Structural Funds for Cultural Projects. Bruxelas, Parlamento Europeu.

Nações Unidas (2008) Creative Economy Report 2008 - The Challenge of Assessing the Creative Economy: Towards Informed Policy-making. Genebra e Nova Iorque: Nações Unidas.

Nações Unidas (2010) Creative Economy Report 2010 - A Feasible Development Option. Genebra e Nova Iorque: Nações Unidas.

Nações Unidas (2013) Creative Economy Report 2013 - Widening Local Development Pathways. Genebra e Nova Iorque: Nações Unidas.

Organização para a Cooperação e Desenvolvimento Económico (2005) Culture and Local Development. Paris: Organização para a Cooperação e Desenvolvimento Económico.

Organização para a Cooperação e Desenvolvimento Económico (2009) The Impact of Culture on Tourism. Paris: Organização para a Cooperação e Desenvolvimento Económico.

Power, Dominic \& Nielsen, Tobias (2010) Priority Sector Report: Creative and Cultural Industries, Europe INNOVA, European Cluster Observatory.

Ritchie Jane \& Lewis, Jane (2003) Qualitative Research Practice: a Guide for Social Science Students and Researchers. Londres: Sage. 
Sacco, Pier Luigi; Ferilli, Guido; Pedrini, Sabrina (2008) "System-wide cultural districts: An introduction from the Italian viewpoint”, in Kagan, Sacha \& Kirchberg, Volker (Org.), Sustainability: A new frontier for the arts and cultures. Frankfurt a.M.: VAS Verlag, pp. 400-460.

Sacco, Pier Luigi; Blessi, Giorgio Tavano; Nuccio, Massimiliano (2009) "Cultural policies and local planning strategies: What is the role of culture in local sustainable development?”, Journal of Art Management, Law, and Society, 39(1): 45-64.

Spinaci, Gianluca \& Vara-Arribas, Gracia (2009) "The European Grouping of Territorial Cooperation (EGTC): New Spaces and Contracts for European Integration”, EIPAScope, 2009 (2): 5-13.

Francisco José Veiga, Professor Catedrático do Departamento de Economia e membro do Núcleo de Investigação em Políticas Económicas (NIPE) da Escola de Economia e Gestão (EEG) da Universidade do Minho. Doutorado em Economia em 1998 pela Universidade da Carolina do Sul (EUA). Leciona e investiga nas áreas da Macroeconomia, Crescimento Económico e Economia Política, tendo 25 artigos publicados em revistas científicas internacionais. Liderou e participou em diversos projetos de investigação financiados pela FCT. Foi diretor do NIPE, do Departamento de Economia e dos cursos de Licenciatura, Mestrado e Doutoramento em Economia da EEG-UM. Presentemente é membro do Conselho Geral da Universidade do Minho. fjeiga@eeg.uminho.pt

Francisco Carballo-Cruz, Professor Auxiliar do Departamento de Economia e membro do NIPE da EEG-UM. Doutorado em Economia em 2007 pela Universidade de Oxford (Reino Unido). Leciona nas áreas de Economia Pública, Economia Regional e de Avaliação de Programas e Políticas Públicas e a sua atividade de investigação desenvolve-se nas áreas da Economia dos Transportes, das Finanças Públicas e da Economia Regional. É membro dos Conselhos Diretivo e Executivo do EURES Transfronteiriço GalizaNorte de Portugal e do Conselho de Administração da TecMinho. É membro permanente do Comité Executivo da European Regional Science Association. Foi recentemente eleito Auditor Interno da Regional Science Association International.

Linda Gonçalves Veiga, Professora Associada com Agregação do Departamento de Economia e membro do NIPE da EEG-UM. Doutorada em Economia em 1999 pela Universidade da Carolina do Sul (EUA). Leciona e investiga nas áreas de Economia e Finanças Públicas e Economia Política, tendo quinze artigos em revistas científicas internacionais. Liderou diversos projetos de investigação financiados pela FCT. Foi Diretora do Departamento de Economia, vice-presidente da EEG e diretora do NIPE. É atualmente diretora do programa de doutoramento em Economia. 